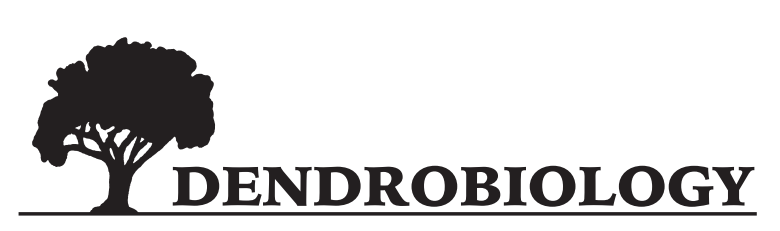

2019, vol. 81, 65-72

http://dx.doi.org/10.12657/denbio.081.008

\author{
Caitlin A. McCavour, Mason T. MacDonald, Rajasekaran R. Lada
}

\title{
Modifying stomatal conductance delays dehydration but not postharvest needle abscission in Abies balsamea
}

Received: 30 April 2019; Accepted: 24 June 2019

\begin{abstract}
Postharvest needle abscission poses a significant challenge to the balsam fir (Abies balsamea L.) Christmas tree industry. Root detachment, and other postharvest handling and transporting factors, lead to a progressive dehydration leading to postharvest needle loss. If this were so, reducing the transpiratory water loss through regulating stomata would be expected to reduce dehydration extending needle retention. This study explored this hypothesis through manipulation of balsam fir stomata using chemical treatments to determine the effect on water uptake, relative water content, and needle abscission. Branches were collected from 70 trees and immediately applied a postharvest treatment of water (control), ABA, fluoridone, BAP, theophylline, potassium nitrate, or dopamine. Stomatal conductance decreased by $27 \%$ after application of ABA and increased by $24 \%, 17 \%$, and $18 \%$ by fluoridone, BA, and potassium nitrate, respectively. Consequently, the ABA treatment resulted in a significantly lower water uptake while fluoridone, BAP, and potassium nitrate all increased water uptake. Despite changes in stomatal conductance and water uptake, there were no significant changes in needle retention. Needle abscission commenced after an average of 12.5 days from postharvest treatment application and reached $100 \%$ completion after an average of 71.9 days. It is possible to manipulate stomatal conductance and water uptake through chemical methods, but such a manipulation does not guarantee superior needle retention. It is proposed that deficiency of certain hormonal signals originating from roots may play a critical role in postharvest needle abscission.
\end{abstract}

Keywords: postharvest, water uptake, Abscisic acid, balsam fir, needle abscission

Address: C. A. McCavour, M. T. MacDonald, R. R. Lada, Department of Plant, Food, and Environmental Sciences, Faculty of Agriculture, Dalhousie University, Bible Hill, NS, B2N 5E3, Canada, e-mail: raj.lada@dal.ca

\section{Introduction}

The Christmas tree industry is of high economic importance in Canada and Nova Scotia. Canada is one of the largest exporters of Christmas trees worldwide, exporting mainly to the United States. The Christmas tree industry is worth approximately CAD 78.4 million in revenue in Canada (Statistics
Canada, 2015). Next to Quebec, Nova Scotia represents the second largest producer of Christmas trees in Canada accounting for CAD 8.6 million in revenue. The most commonly produced Christmas tree in the Atlantic provinces is balsam fir (Abies balsamea L.), which is popular due to its appealing conical shape, sweet fragrance, and blue-green color (Thiagarajan et al., 2016). 
Needle abscission poses one of the greatest challenges to producers in the Christmas tree industry, as one in every three trees suffer from increased needle abscission (MacDonald, 2010). Abscission refers to the removal of a plant organ caused by developmental or environmental stresses. Abscission occurs among a small layer of cells that are distinct due to high reproduction rates and lack of growth called the abscission zone. The abscission zone in balsam fir can be seen through an electron microscope and identified as small, irregularly shaped cells between the base of the needle and the stem (Thiagarajan et al., 2016). Abscission zone cells respond differently to certain hormones and are softened by catalytic enzymes. This softening allows the Golgi apparatus and endoplasmic reticulum to expand within the cell until the cell wall breaks allowing for the needle to be detached from the branch (Sagee et al., 1980).

The timing of needle abscission in balsam fir follows a sigmoidal curve where abscission is less likely to occur within the first two weeks, then begins to ensue at an exponential rate, and finally declines as there are less needles to fall off (Lada \& MacDonald, 2015). Though the pattern of needle loss is relatively simple, it is influenced by a multitude of factors. One factor affecting needle abscission characteristics is genotype, where postharvest needle abscission has been shown to vary from 6 to 60 days even during dehydration between different genotypes (MacDonald et al., 2014). Environmental conditions in autumn, such a decreasing temperature and photoperiod, typically increase needle retention (Thiagarajan et al., 2013; MacDonald et al., 2016). However, increases in hormones, such as abscisic acid (ABA) or ethylene, typically decreases needle retention (Thiagarajan et al., 2013; MacDonald, 2010).

Several studies have shown that increases in postharvest needle abscission are associated with the hydraulic properties of the tree. Water uptake through the xylem is of particular importance because needle abscission tends to begin in earnest once rates decrease to $0.05 \mathrm{~mL} \mathrm{~g}^{-1} \mathrm{~d}^{-1}$ in branches or cut whole trees (Lada \& MacDonald, 2015). The dramatic decrease in water uptake is caused by the detachment of roots decreasing the water transport potential gradient (Sperry et al., 1994). The mechanism of water uptake is influenced by several factors, including water availability, hydraulic conductance, stomatal conductance, and vapor pressure deficit. Lada and MacDonald (2015) discussed how a decrease in xylem pressure potential due to blockage of the xylem correlated positively with needle abscission (Lada \& MacDonald, 2015). It was also suggested that poor water quality from high bacterial growth in Christmas tree stands may result in xylem blockage and poor water uptake rates (Lada et al., 2016). It should also be considered many other factors can affect postharvest water uptake, such as leached compounds from Christmas tree sap, occlusion of xylem elements by resin, or xylem cavitation (MacDonald et al., 2016; van Doorn, 1999).

Stomata are small pores on the underside of plant leaves that open and close in relation to transpiration rate (Pantin et al., 2013). As regulators of gas exchange and transpiration through the plant, the opening and closing of stomata play a significant role in maintaining the postharvest water status of the plant (MacInnes, 2015). Stomata will close after harvest to conserve water by lowering the transpiration rate, which results in a sharp decrease in stomatal conductance and water uptake. Stomatal closure often occurs as a stress response to water deficit, where a loss in turgor and ABA act on guard cells to close stomata thereby conserving water (Brodribb \& McAdam, 2013). Initial postharvest needle stomatal conductance is typically $20-25 \mathrm{mmol} \mathrm{m}^{-2} \mathrm{~s}^{-1}$ in balsam fir, but values may decrease by up to $80 \%$ in the first week (MacInnes, 2015). Decreased stomatal conductance is linked to decreased water uptake and accelerated needle loss. Creating an environment that promotes stomatal aperture could allow water uptake to continue, provided there is no xylem blockage (MacInnes, 2015).

The opening and closing of stomata can be manipulated through various compounds. Previously mentioned is $A B A$, which reduces stomatal aperture by reducing the turgor of guard cells located around the stomata (Brodribb \& McAdam, 2013). In contrast, fluoridone inhibits the biosynthesis of endogenous ABA by blocking the desaturation step of the carotenoid biosynthesis pathway in plants. It is expected that this inhibition will reverse the effects of ABA on stomata, increasing stomatal conductance (Chae et al., 2004; Lee et al., 2015). BAP is a synthetic cytokinin, which are a group of plant growth regulators that promote shoot growth and division of plant cells (Schaller et al., 2014). Certain cytokinins have also been known to reduce senescence and needle abscission (MacDonald \& Lada, 2017). Roots of bean leaves inserted in BAP have shown to have opposite effects to ABA thus, opening the stomata allowing higher transpiration rate (Pospisilova, 2003). Theophylline, a methylated xanthine, can act as a cytokinin inhibitor as it is shown to decrease BAP metabolism in radish cotyledons (Tao et al., 1991). Dopamine acts as a cytokinin antagonist and therefore, opposes the effects of cytokinins on stomatal conductance (Elstner et al., 1976). Finally, potassium improves stomatal control and increases drought resistance, which can be supplied as potassium nitrate or potassium chloride (van den Driessche, 1991).

Increased stomatal conductance can result in higher water uptake, assuming water is available and hydraulic conductivity is not limiting. Maintaining water uptake rates higher than the $0.05 \mathrm{~mL} \mathrm{~g}^{-1} \mathrm{~d}^{-1}$ 
critical value should delay postharvest needle abscission. The purpose of this study was to determine if (1) stomatal conductance could be manipulated using the six aforementioned chemicals as treatments, (2) to determine if increased stomatal conductance increases the water uptake and relative water content (RWC) in balsam fir, and (3) to determine if the manipulation of stomatal aperture modifies needle retention.

\section{Materials and Methods}

\section{Experimental design}

This experiment followed a completely randomized blocks design, where the factor of interest was provision of treatments to modify stomatal aperture. There were 7 treatments: water (as a control), $100 \mathrm{mg} \mathrm{L}^{-1}$ ABA, $20 \mathrm{mg} \mathrm{L}^{-1}$ fluoridone, $10 \mathrm{mg} \mathrm{L}^{-1}$ BAP, $20 \mathrm{mg}$ $\mathrm{L}^{-1}$ theophylline, $200 \mathrm{mg} \mathrm{L}^{-1}$ potassium nitrate, and $15 \mathrm{mg} \mathrm{L}^{-1}$ dopamine (Sigma-Aldrich, Ontario, Canada). The concentrations of treatments were based on preliminary results (MacDonald, unpublished). The blocking factor was tree, in which 5 different trees were randomly selected for the experiment. Two branches were collected from each tree, which required a total of 70 branches. The response variables were needle stomatal conductance, water uptake, relative water content, and needle abscission. Each response variable is described in more detail below.

\section{Sample collection}

A sample of 70 branches was collected from five different trees from a balsam fir orchard in Hilden, Nova Scotia, Canada $\left(45.30^{\circ} \mathrm{N}, 63.32^{\circ} \mathrm{W}\right)$ on October 23,2016 . The mean temperature of October prior to sample collection was $8.8^{\circ} \mathrm{C}$, though there was one frost event. Branches containing the last two years of growth were taken from the same facing direction and general location of each tree. Branches were transported to the lab with cut end in distilled water.

The protocols for branch preparation and display were based on work described in MacDonald (2010). Branches were provided a fresh cut with stems submerged in distilled water to reduce risk of cavitation. Branches were randomly assigned to a treatment and placed in $100 \mathrm{ml}$ amber bottles containing the designated treatments. Cotton batting was placed around the opening of the amber bottle and branch to prevent solution loss through evaporation and provide additional stability to the branch. Samples were placed in a laboratory in conditions that simulated household conditions: $20^{\circ} \mathrm{C}, 40 \%$ humidity, and 80 $\mu \mathrm{mol} \mathrm{m}{ }^{-2} \mathrm{~s}^{-1}$ light supplied by fluorescent lights for 16 hours each day followed by 8 hours of darkness.

\section{Postharvest needle abscission}

Needle abscission was measured by collecting the number of needles that would fall after a 'finger run' test each day, where each branch would be brushed gently between the thumb and forefinger at a constant pressure to dislodge abscised needles. The mass of those needles was measured fresh and after oven drying. Needle abscission was recorded as both needle abscission commencement (NAC) and needle retention duration (NRD). NAC was defined as the length of time required for a branch to abscise $1 \%$ of its needles and NRD was defined as the length of time required to abscise $100 \%$ of needles (MacDonald et al., 2016). Percentage needle loss was also calculated using the following formula:

$$
\% \text { Needle loss }=\frac{\text { Daily Needle Mass Lost }}{\text { Total Cumulative Needle Mass }} \times 100 \text {. }
$$

\section{Stomatal conductance}

Needle stomatal conductance $\left(\mathrm{mmol} \mathrm{m} \mathrm{m}^{-2} \mathrm{~s}^{-1}\right)$ was measured using an SC-1 steady state diffusion leaf porometer (Meter Environment, Pullman, WA). The sensor was attached to needles so that the sensor was completely covered, allowing for estimation of area. Readings were taken from the same location on each branch until (a) readings were 0 for three consecutive weeks or (b) there were not enough needles left on branches to cover sensor. Porometer readings are subject to fluctuations and readings were taken at one minute after placing sensor on needles, which allowed measurements to stabilize.

\section{Water uptake}

Water uptake $\left(\mathrm{mL} \mathrm{g}^{-1} \mathrm{~d}^{-1}\right)$ was measured gravimetrically. Branches were gently removed from the bottles and each bottle was weighed every sampling day. The volume of liquid could then be calculated by subtracting the initial weight of an empty bottle. Daily water uptake was calculated using the following equation:

$$
\text { Daily water uptake }=\frac{M_{n}-M_{n+1}}{\Delta \mathrm{t} \times M_{\text {branch }}},
$$

where $M_{n}$ is the mass of the system from the previous data collection, $M_{n+1}$ is the mass of the system from the current data collected, $M_{\text {branch }}$ represents the mass of the branch, and $\Delta \mathrm{t}$ represents the amount of time in days between each data collection.

\section{Relative water content}

Measurement of relative water content was modified from MacDonald and Lada (2014). The fresh 
mass $\left(M_{f}\right)$ of each branch was recorded at initial cut and then placed in distilled water. After $24 \mathrm{~h}$, the branch was weighed again at full turgidity $\left(\mathrm{M}_{\mathrm{t}}\right)$. Branches were then dried at $90^{\circ} \mathrm{C}$ for $24 \mathrm{~h}$ at the end of the experiment and weighed to obtain dry mass $\left(\mathrm{M}_{\mathrm{d}}\right)$. Fresh and dry mass of needles loss were accounted for in calculations. RWC was then calculated using the following equation:

$$
R W C=\frac{M_{f}-M_{d}}{M_{t}-M_{d}}
$$

\section{Statistical analysis}

Each response variable was submitted to a general linear model in Minitab 18 (Minitab Inc., State College, PA, USA) using chemical treatment as the factor of interest and tree as the blocking factor. Residuals were tested for normality, homogeneity, and independence. Needle abscission, stomatal conductance, and water uptake each required a power transformation to exponent 0.25 to improve normality and homegeneity. All response variables were submitted to analysis of variance to determine whether at least one treatment had a significant effect. Tukey's multiple mean comparison was used to separate means when significant differences were detected at $5 \%$ significance.

\section{Results}

\section{Stomatal conductance and water relations}

There was a treatment effect $(P=0.003)$ on stomatal conductance (Fig. 1). The average needle stomatal

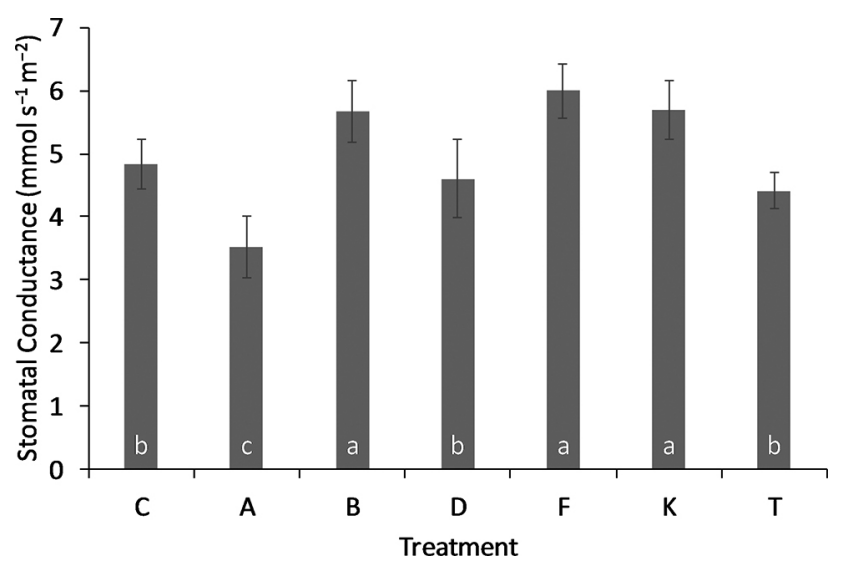

Fig. 1. Effect of 6 treatments and a control (water) on balsam fir average stomatal conductance within the first 3 weeks of harvest. Means were calculated from a total of 10 replicates for each treatment and error bars represent standard error. Letter groups were calculated from Tukey's multiple mean comparison at $\alpha=0.05$

C - control, A - abscisic acid, B - 6-benzylaminopurine, D - dopamine, $\mathrm{F}$ - fluoridone, $\mathrm{K}$ - potassium nitrate, and $\mathrm{T}$ - theophylline.

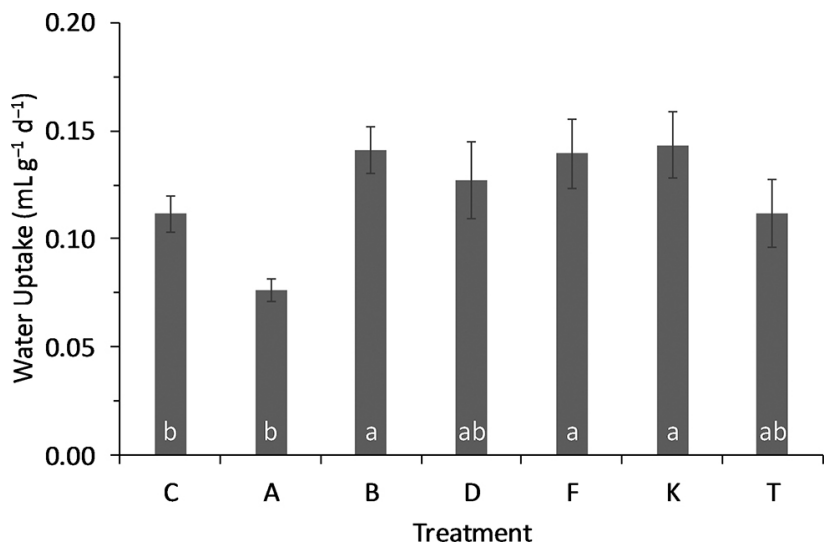

Fig. 2. Effect of 6 treatments and a control (water) on balsam fir average water uptake within the first 3 weeks of harvest. Means were calculated from a total of 10 replicates for each treatment and error bars represent standard error. Letter groups were calculated from Tukey's multiple mean comparison at $\alpha=0.05$

C - control, A - abscisic acid, B - 6-benzylaminopurine, D - dopamine, $\mathrm{F}$ - fluoridone, $\mathrm{K}$ - potassium nitrate, and $\mathrm{T}$ - theophylline.

conductance for a water-fed control was $4.83 \mathrm{mmol} \mathrm{s}^{-1}$ $\mathrm{m}^{-2}$. Fluoridone, BAP, and potassium nitrate increased average needle stomatal conductance by $24 \%, 17 \%$, and $18 \%$, respectively. Xylem-fed ABA decreased needle stomatal conductance to $3.53 \mathrm{mmol} \mathrm{s}^{-1} \mathrm{~m}^{-2}(27 \%$ decrease). No other xylem-fed treatments had a different stomatal conductance than the control.

There was also a treatment effect $(P=0.010)$ on water uptake (Fig. 2). Fluoridone, BAP, and potassium nitrate increased water uptake by $25 \%, 27 \%$, and $29 \%$, respectively. Xylem-fed ABA decreased water uptake to $0.076 \mathrm{~mL} \mathrm{~g}^{-1} \mathrm{~d}^{-1}$ (32\% decrease). No other xylem-fed treatments had a different water uptake than the control. Consequently, there was a linear positive correlation between water uptake and needle stomatal conductance $(P<0.001)$ (Fig. 3$)$.

There was a treatment effect $(P<0.001)$ on dehydration, indicated by the average RWC (Fig. 4). The

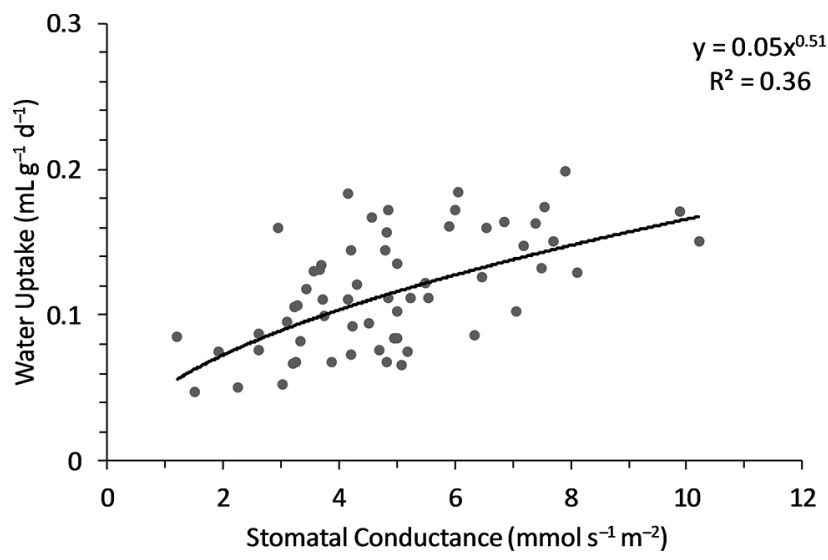

Fig. 3. Positive relationship between stomatal conductance and water uptake in balsam fir branches. Fitted line represents a power function $\mathrm{N}-70$. 


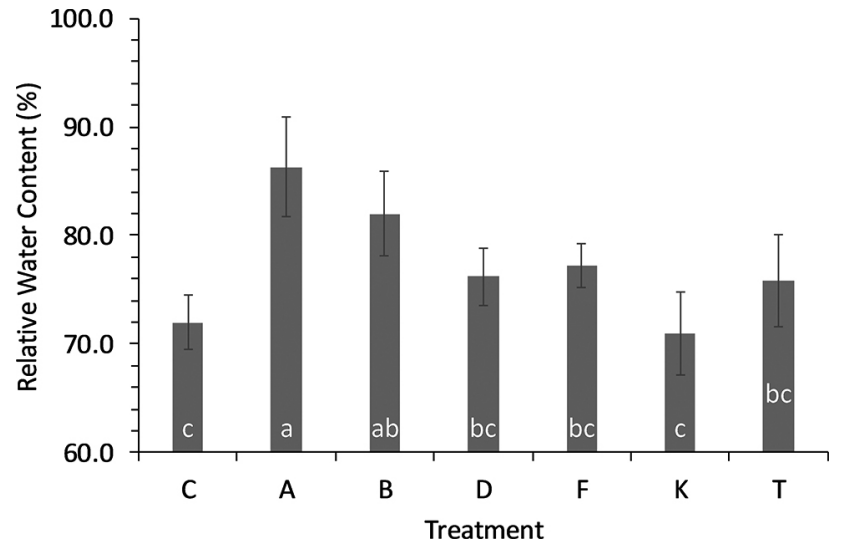

Fig. 4. Effect of 6 treatments and a control (water) on balsam fir relative water content within the first 3 weeks of harvest. Means were calculated from a total of 10 replicates for each treatment and error bars represent standard error. Letter groups were calculated from Tukey's multiple mean comparison at $\alpha=0.05$

C - control, A - abscisic acid, B - 6-benzylaminopurine, D - dopamine, $\mathrm{F}$ - fluoridone, $\mathrm{K}$ - potassium nitrate, and $\mathrm{T}-$ theophylline.

average RWC for the water-fed control was $72.0 \%$. However, the xylem-fed ABA and BAP treatment had higher RWC of $86.3 \%$ and $82.0 \%$, respectively. No other treatments were different from the control.

Including balsam fir trees as a blocking factor was an important part of this analysis. The F-values ranged from 3.68 to 7.08 , which suggested that trees contributed to the substantial variation in needle stomatal conductance, water uptake, and RWC.

\section{Needle abscission}

The overall progression of needle abscission in all treatments followed a sigmoidal curve (Fig. 5), though there were no differences between treatments. There was no treatment effect on abscission in the first three weeks $(P=0.141)$, NAC $(P=$ $0.350)$, or NRD $(P=0.373)$ in this experiment (Fig. 6; Fig. 7). The water-fed balsam fir branches lost an

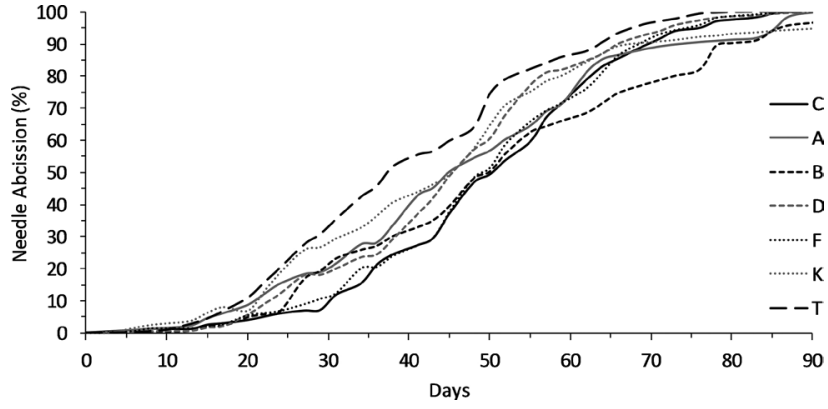

Fig. 5. Progression of needle abscission of balsam fir branches from 7 treatments throughout 90 days postharvest. The means for each treatment were calculated from a total of 10 replicates. Error bars were not included because they made the graph very difficult to see, but there were no significant differences $(\alpha=0.05)$ in needle abscission throughout the experiment

C - control (water), A - abscisic acid, B - 6-benzylaminopurine, $\mathrm{D}$ - dopamine, $\mathrm{F}$ - fluoridone, $\mathrm{K}$ - potassium nitrate, and $\mathrm{T}$ theophylline.

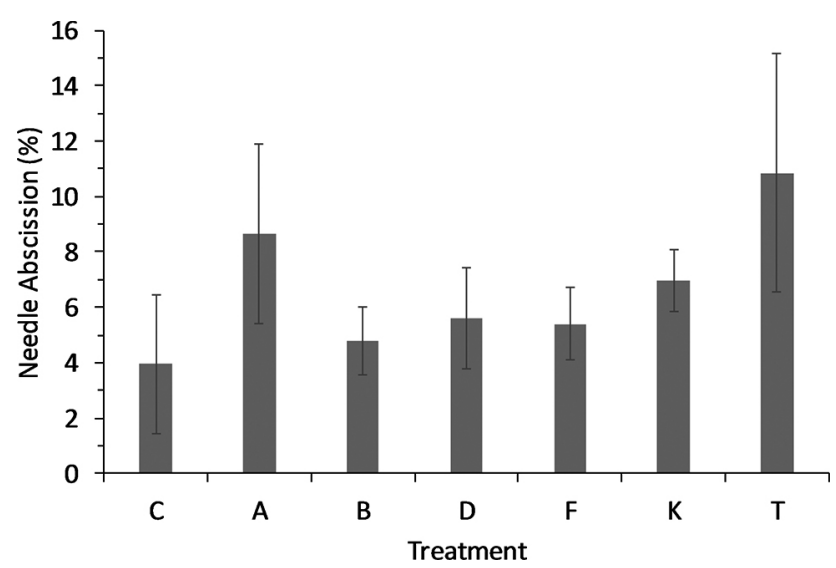

Fig. 6. Effect of 6 treatments and a control (water) on balsam fir needle abscission within the first 3 weeks of harvest. Means were calculated from a total of 10 replicates for each treatment and error bars represent standard error. Letter groups were calculated from Tukey's multiple mean comparison at $\alpha=0.05$

C - control, A - abscisic acid, B - 6-benzylaminopurine, D - dopamine, $\mathrm{F}$ - fluoridone, $\mathrm{K}$ - potassium nitrate, and $\mathrm{T}$ - theophylline.
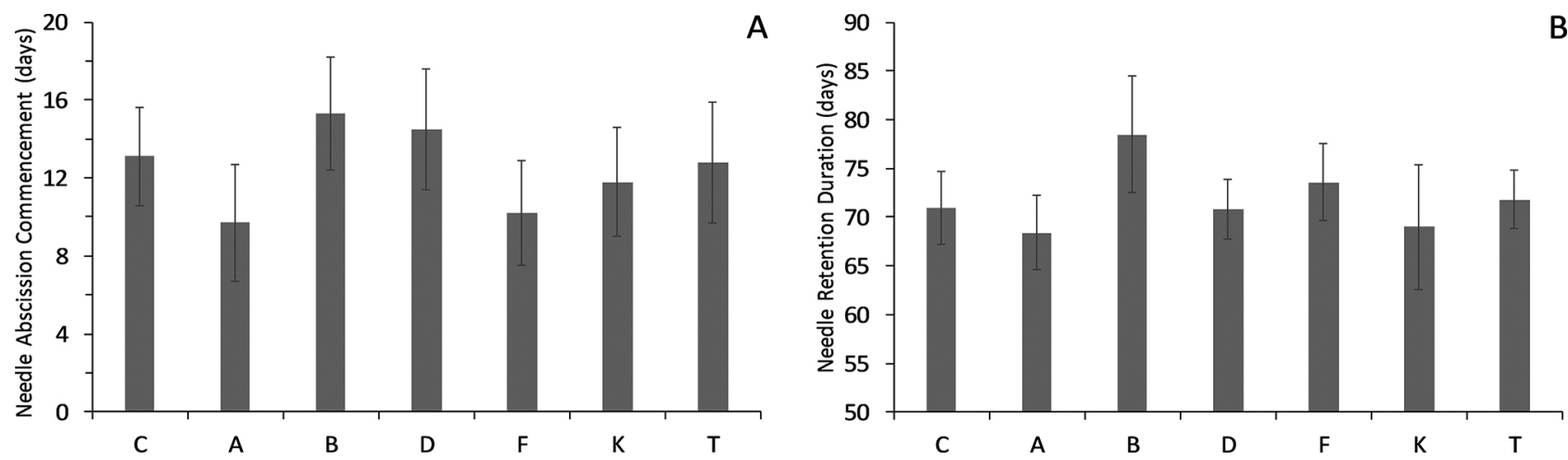

Fig. 7. Effect of 6 treatments and a control (water) on balsam fir A) needle abscission commencement and B) needle retention duration. Means were calculated from a total of 10 replicates for each treatment and error bars represent standard error

C - control, A - abscisic acid, B - 6-benzylaminopurine, D - dopamine, F - fluoridone, $\mathrm{K}$ - potassium nitrate, and $\mathrm{T}$ - theophylline 
average of $3.95 \%$ of their needles in the first three weeks and required 71.0 days to complete abscission. Although branches xylem-fed theophylline or ABA lost an average of $10.84 \%$ or $8.66 \%$ of needles in three weeks, respectively, there was no effect. Similarly, needle retention duration ranged from 68.4 to 78.5 days with no treatments contributing an effect. The F-value for needle abscission was 2.27 , which indicates that balsam fir trees contributed substantial variation to postharvest needle abscission.

\section{Discussion}

Several chemicals (ABA, fluoridone, BAP, and potassium nitrate) modified needle stomatal conductance as expected. ABA was the only treatment to decrease stomatal conductance, which was expected since ABA reduces potassium salt channel activity within the cell membrane and causes guard cells around the stomata to lose their turgor (Brodribb \& McAdam, 2013; MacRobbie, 1995). BAP, fluoridone, and potassium nitrate each increased stomatal conductance, which is also what was expected. Fluoridone blocks the desaturation process of the carotenoid biosynthesis pathway, a precursor to $\mathrm{ABA}$, and should lower endogenous ABA. Consequently, fluoridone should negate the effects of ABA on stomata (Chae et al., 2004; Lee et al., 2015). BAP is a synthetic cytokinin and an increase in certain cytokinins has been associated with reduced senescence and needle abscission in balsam fir (MacDonald \& Lada, 2017). Conversely, low cytokinin concentrations were associated with senescence (Noodén et al., 1990). Finally, potassium nitrate provides $\mathrm{K}^{+}$, which move through inward rectifying channels to supply turgor to guard cells and keep stomata opened (Daszkowska-Golec \& Szarejko, 2013).

Not all treatments affected stomata as expected. Dopamine is considered a cytokinin antagonist, which may also contribute to ethylene evolution (Elstner et al., 1976). Theophylline acts as a cytokinin inhibitor shown in a study conducted on radish cotyledons where BAP metabolism was slowed (Tao et al., 1991). Due to their negative effects on cytokinins, dopamine and theophylline were expected to decrease needle stomatal conductance, but neither had any effect on stomatal conductance in our study. It is possible that the dose of each chemical was too low, or perhaps dopamine and theophylline have limited efficacy when xylem-fed. It should also be noted that these compounds could have multiple roles in plant physiology. For example, although dopamine may be a cytokinin antagonist, it is also a powerful antioxidant and has been shown to alleviate water deficit or saline stress (Liang et al., 2018; Li et al., 2014). Li et al. (2014) concluded that dopamine acted not only at the level of antioxidant defense, but also by regulating other mechanisms of ion homeostasis.

It was expected that there would be a positive relationship between needle stomatal conductance and water uptake. Roots are detached at harvest and, therefore, water uptake should correspond with stomatal conductance (Sperry et al., 1994). Water uptake was correlated with stomatal conductance in our study, meaning that branches with high stomatal conductance generally also had high water uptake. ABA decreased water uptake while BAP, fluoridone, and potassium nitrate all increased water uptake presumably through mechanisms described previously. Unlike water uptake, RWC was not correlated with stomatal conductance. Branches treated with ABA and BAP each dried out slower than the control, despite BAP having a high stomatal conductance and water uptake than the control. It must be noted that BAP has multiple beneficial effects on plants that may contribute to reduced dehydration, such as reducing stress related reactive oxygen species and enhancing the activity of antioxidant enzymes (Zavaleta-Mancera et al., 2007). This also suggests no decrease in hydraulic conductivity along the stem path.

Needle abscission in our study followed a sigmoidal curve for each treatment, which is the typical postharvest response in balsam fir (Lada \& MacDonald, 2015). It was expected that treatments that successfully modified water uptake and stomatal conductance would also modify postharvest abscission. However, there were no differences in needle abscission due to any treatment. Past studies have suggested that the inherent variability in needle abscission resistance between trees could make it difficult to determine a treatment effect (MacDonald et al., 2014), but this variability should have been accounted for in our study since tree was a blocking factor. The relatively high F-values obtained in our analysis do tend to agree that blocking by tree was prudent. However, it is often difficult to further increase needle retention in trees that naturally possess superior needle retention (MacDonald et al., 2014). Branches with a NRD of greater than 40 days are referred to as high needle retaining trees (MacDonald et al., 2014) and NRD in our study was approximately 71 days, though our branches were not dehydrated. Still, there is some evidence that the branches used may have had naturally high NRD and made it difficult to discern any treatment effect in our experiment. Another possibility is that branches were undergoing cold acclimation during harvest. Cold acclimation begins early in the season, when photoperiod and temperatures begin to decrease (MacDonald et al., 2016). One effect of cold acclimation is referred to as genotypic convergence, where the average NRD of all genotypes tends to increase and become more tightly clustered together (MacDonald et al., 2014). 
It is important to note that several of the chemical treatments used in our study do not only affect stomatal function. For example, ABA both promotes stomatal closure and reduces hydraulic conductivity in plants (Pantin et al., 2013; Finkelstein, 2013). However, ABA also increases the activity of reactive oxygen species (Gayatri et al., 2013) and promotes senescence-associated genes (Finkelstein, 2013). It is possible that the combination of positive and negative effects could result in no net change in postharvest abscission.

In conclusion, $\mathrm{ABA}$ decreased stomatal conductance and water uptake while BAP, fluoridone, and potassium nitrate each increased stomatal conductance and water uptake. However, neither increasing nor decreasing stomatal aperture had any effect on postharvest needle abscission. Ultimately, our study does not provide evidence that modifying stomatal conductance or water uptake alone is an effective method of delaying postharvest needle abscission in balsam fir, and reveals that postharvest needle abscission is regulated by mechanisms other than just maintaining positive water status.

Funding provided by Natural Science and Engineering Research Council, Atlantic Innovation Fund, ACOA, Christmas Tree Council of Nova Scotia, SMART Christmas Tree Research Cooperative, NS Department of Natural Resources.

\section{References}

Brodribb TJ \& McAdam SAM (2013) Abscisic acid mediates a divergence in the drought response of two conifers. Plant Physiology 162: 1370-1377.

Chae SH, Yoneyama K, Takeuchi Y \& Joel DM (2004) Fluoridone and norflurazon, carotenoid-biosynthesis inhibitors, promote seed conditioning and germination of the holoparasite Orobanche minor. Physiology Plantarum 120: 328-337.

Daszkowska-Golec A \& Szarejko I (2013) Open or close the gate - stomata action under the control of phytohormones in drought stress conditions. Frontiers in Plant Science 4: 1-16.

Elstner EF, Konze JR, Selman BR \& Stoffer C (1976) Ethylene formation in sugar beet leaves. Evidence for the involvement of 3-hydroxytyramine and phenoloxidase after wounding Plant Physiology 58: 163-168.

Finkelstein R (2013) Abscisic acid synthesis and response. Arabidopsis Book. American Society of Plant Biologists. doi:10.1199/tab.0166.

Gayatri G, Agurla S \& Raghavendra AS (2013) Nitric oxide in guard cells as an important secondary messenger during stomatal closure. Frontiers in Plant Science 4: 425. doi:10.3389/ fpls.2013.00425.
Lada RR \& MacDonald MT (2015) Understanding the physiology of postharvest needle abscission in balsam fir. Frontiers in Plant Science 6: 1-11.

Lada RR, MacDonald MT \& West RR (2016) Physiology of postharvest needle abscission in balsam fir: water quality modulates postharvest needle abscission. Acta Horticulturae 1119: 111-120.

Liang B, Gao T, Zhao Q, Ma C, Chen Q, Wei Z, Li C, Li C \& Ma F (2018) Effects of exogenous dopamine on the uptake, transport, and resorption of apple ionome under moderate drought. Frontiers in Plant Science 9: 1-14.

Li C, Sun X, Chang C, Jia D, Wei Z, Li C \& Ma F (2014) Dopamine alleviates salt-induced stress in Malus hupehensis. Physiology Plantarum 153: 584-602.

Lee YI, Chung MC, Yeung EC \& Lee N (2015) Dynamic distribution and the role of abscisic acid during seed development of a lady's slipper orchid, Cypripedium formosanum. Annals of Botany 116: 403-411.

MacDonald MT (2010) Physiological significance of ethylene in post-harvest needle abscission in root-detached balsam fir. PhD Thesis, Laval University, Quebec, Canada.

MacDonald MT \& Lada RR (2014) Biophysical and hormonal changes linked to postharvest needle abscission in balsam fir. Journal of Plant Growth Regulation 33: 602-611.

MacDonald MT \& Lada RR (2017) Changes in endogenous hormone levels explains seasonal variation in balsam fir needle abscission patterns. Journal of Plant Growth Regulation 36: 723-733.

MacDonald MT, Lada RR \& Veitch S (2016) Seasonal changes in balsam fir needle abscission patterns and links to environmental factors. Scandinavian Journal of Forest Research 32: 438-445.

MacDonald MT, Lada RR, Veitch S \& Thiagarajan A (2014) Postharvest needle abscission resistance of balsam fir (Abies balsamea) is modified by harvest date. Canadian Journal of Forest Research 44: 1394-1401.

MacDonald MT, Lada RR, West RR \& Nelson KL (2016) Xylem-fed maple sap accelerates balsam fir needle abscission but can delay water loss in spring and autumn. Dendrobiology 76: 157-164.

MacInnes R (2015) Determining the link between certain hydraulic properties and postharvest needle abscission in balsam fir (Abies balsamea (L.) Mill.). M.Sc. Thesis, Dalhousie University, Halifax, Nova Scotia, Canada.

MacRobbie EAC (1995) Effects of ABA on $86 \mathrm{Rb}^{+}$ fluxes at plasmalemma and tonoplast stomatal guard cells. Plant Journal 7: 835-843.

Noodén LD, Singh S \& Letham DS (1990) Correlation of xylem sap cytokinin levels with monocar- 
pic senescence in soybean. Plant Physiology 93: 33-39.

Pantin F, Monnet F, Jannaud D, Costa JM, Renaud J, Muller B, Simonneau T \& Genty B (2013) The dual effect of abscisic acid on stomata. New Phytologist 197: 65-72.

Pospisilova J (2003) Interaction of cytokinins and abscisic acid during regulation of stomatal opening in bean leaves. Photosynthetica 41: 49-56.

Sagee O, Goren R \& Riov J (1980) Abscission of citrus leaf explants interrelationships of abscisic acid, ethylene, and hydrolytic enzymes. Plant Physiology 66: 750-753.

Schaller GE, Street IH \& Kieber JJ (2014) Cytokinin and the cell cycle. Current Opinions in Plant Biology 21: 7-15.

Sperry JS, Nichols KL, Sullican JEM \& Eastlack SE (1994) Xylem embolism in ring-porous, diffuse-porous, and coniferous trees of northern Utah and interior Alaska. Ecology 75: 1736-1752.

Statistics Canada (2015) Christmas trees...by the numbers. https://www.statcan.gc.ca/eng/dai/ smr08/2017/smr08_222_2017.

Tao GQ, Letham DS, Hocart CH \& Summons RE (1991) Inhibitors of cytokinin metabolism III. The inhibition of cytokinin N-glucosylation in radish cotyledons. Journal of Plant Growth Regulation 10: 179-185.

Thiagarajan A, Lada R, Pepin S, Forney C, Desjardins Y \& Dorais M (2013) Temperature and photoperiod influence of postharvest needle abscission of selected balsam fir (Abies balsamea L. (Mill.)) genotypes by modulating ABA levels. Journal of Plant Growth Regulation 32: 843-851.

Thiagarajan A, MacDonald MT \& Lada R (2016) Environmental hormonal physiology of postharvest needle abscission in Christmas trees. Critical Reviews in Plant Sciences 35: 1-17.

van den Driessche R (1991) Mineral nutrition of conifer seedlings. CRC Press, Boca Raton, Florida, pp. 233-234.

van Doorn WG (1999) Vascular occlusion in cut flowers. I. General principles and recent advances. Acta Horticulturae 482: 59-64.

Zavaleta-Mancera HA, Lopez-Delgado H, Loza-Tavera $\mathrm{H}$, Mora-Herrara M, Trevilla-Garcia C, Vargas-Suarez M \& Ougham H (2007) Cytokinin promotes catalase and ascorbate peroxidase activities and preserves the chloroplast integrity during dark senescence. Journal of Plant Physiology 164: 1572-1582. 